\title{
EDITORIAL
}

\section{LA OTRA GUERRA DEL PACÍFICO ${ }^{1}$}

\author{
THE OTHER WAR OF THE PACIFIC
}

\author{
Alberto Díaz Araya ${ }^{2}$ \\ José Chaupis Torres ${ }^{3}$ \\ Eugenio Sánchez Espinoza ${ }^{4}$
}

El episodio bélico conocido como la guerra del Pacífico (1879-1883) o del Salitre, ha marcado el devenir histórico de los Estados chileno-peruanoboliviano, constituyéndose como un hito que modificó los territorios como también ha modelado las identidades nacionales, tanto en las metrópolis como en la periferia. Así, la guerra se ha transformado en un punto de inflexión que subraya en un antes y un después la historia local más allá de las fronteras imaginadas en las esferas del poder, que diseñaron desde sus epicentros políticos y aposentos oligárquicos el acto de pugnar de los pueblos, además de colmatar de símbolos nacionalistas los viejos terruños virreinales, reproduciendo lealtades patrióticas en los que habitan aquí o allá los espacios liminales fronterizos.

Pero la guerra, más allá de los campos de batallas o del poderío de las armas de los bandos que colisionaron, encierra a una serie de actores que entre campañas militares o la muerte en el combate, ilustran una compleja realidad social, económica y cultural muchas veces no descrita en las páginas gloriosas de los héroes que la historia oficial inmortalizó. Siguiendo este derrotero, y en el marco del simposio "Actores subalternos durante la Guerra del Pacífico" como parte del IX Congreso Internacional de Etnohistoria celebrado en Arica, Chile (2014), se buscó reflexionar en torno a las redes e interacciones entre los distintos actores sociales y los cambios producidos por ellos a consecuencia del estallido de la guerra. La apertura a estos enfoques intenta cambiar las miradas dicotómicas y excluyentes sobre ciertos personajes ausentes en la literatura oficial, por una imagen crítica de la guerra que considere la voz de esos otros que participaron anónimamente en el desarrollo del conflicto.

En este contexto, parte del conjunto de artículos del presente número de DIÁLOGO ANDINO está dedicado a los sujetos marginales de la guerra, como también a visiones desde la literatura escolar de los países involucrados, los imaginarios circulantes en la prensa de época, la versiones de los extranjeros o la disposición que adquiere la población en el territorio que alguna vez fuera escenario de la contienda. Por otra parte, incluimos artículos que abordan problemáticas recurrentes sobre las fronteras nacionales poderosamente dinámicas como la de los países Latinoamericanos, como lo constituyen las migraciones o las demandas territoriales.

Los trabajos que publicamos son los siguientes: Claudio Véliz examina cómo se va instalando la figura del "roto" a través de un discurso nacionalista, en una condición de subalternidad masculina simbólica. A través del análisis de la editorial del periódico El Pacifico en la década de 1950 Véliz va identificando como a través de este dispositivo cultural se va constituyendo una apropiación de valores como el coraje, la audacia y lealtad quedando anclados este discurso de nacionalidad representado por el "roto", quien habría desplegado todos su dotes en el escenario bélico de la guerra.

Los historiadores José Chaupis y Ricardo Aguilar estudian la normativa y mecanismos jurídicos de las elecciones peruanas en la segunda mitad del siglo

\footnotetext{
Publicación producida en el marco del proyecto FONDECYT 1151514 y Convenio de Desempeño UTA-MINEDUC. Universidad de Tarapacá, Departamento de Ciencias Históricas y Geográficas, Arica, Chile: Correo electrónico: albertodiaz@ uta.cl

3 Universidad Nacional Mayor de San Marcos, Lima, Perú. Correo electrónico: jotache5@ hotmail.com

4 Universidad de Tarapacá, Departamento de Ciencias Históricas y Geográficas, Arica, Chile: Correo electrónico: esanchez@ uta.cl
} 
XIX. En este sentido, discuten que la evolución jurídica del Perú es muy dinámica desde la perspectiva de la inclusión de los sujetos marginales a los procesos eleccionarios, analizando su actuación en las contiendas político electorales peruanas, que tuvo como principales protagonistas al Partido Nacional y el Partido Civil. Seguidamente, Nelson Pereyra analiza a los campesinos de Ayacucho (Perú) en el contexto de la guerra del Pacifico, y su relación con el Estado peruano. El autor señala que la guerra contra Chile generó un nacionalismo sui generis en los campesinos ayacuchanos a la vez que vivían en tensión con los gamonales, manteniendo su actuación política de resistencia frente a estos hacendados, pese a que la región se transformó en un "apéndice" de la campaña de la Breña. Sin embargo, Pereyra concluye que los campesinos decimonónicos no son subalternos por cuanto en Ayacucho no estructuraron una "comunidad republicana" alternativa al Estado, basada en la alteridad, la particularidad y la "tradicionalidad", como sugiere la teoría de los estudios subalternos, sino más bien dialogaron y reprodujeron las pautas del Estado, acudiendo a las instancias judiciales y utilizar su discurso oficial para enfrentar a los gamonales y lograr el acceso a la propiedad de la tierra.

El profesor Mauricio Rubilar analiza el discurso que formuló la prensa católica de la provincia de Concepción (Chile) acerca del papel de las mujeres, los sectores populares y la movilización ciudadana durante los años de la guerra. El autor describe la construcción de un imaginario social con proyección nacional a partir de un discurso político y doctrinario de la prensa regional, que buscó manejar el comportamiento y el compromiso patriótico de determinados sectores de la sociedad chilena. En otro plano, Gerardo Trillo se ocupa de una manifestación de extranjeros en la ciudad de Buenos Aires en 1881 debido a la ocupación de Lima por parte de las tropas chilenas, acción que se vio reflejada en la prensa bonaerense. Trillo declara que la historiografía tradicional ha instalado el discurso patriótico que ha ocultado la trascendencia que tuvo el conflicto para diversos grupos que no necesariamente se vieron involucrados directamente en la guerra, como lo constituyó el caso de la comunidad de extranjeros y su Indignation Meeting registrado en la Argentina

El investigador Emilio Rosario realiza un examen del texto Mi Manuel de la autora francesa Adriana de Verneuil. Dicha autora vierte en Mi Manuel sus experiencias vividas durante la guerra francoprusiana y que la llevan a realizar una comparación con la contienda del Pacifico, en la que aprecia los mismos abusos del conflicto europeo, llevándola a tomar parte por la causa peruana. Desde una perspectiva analítica profunda, el autor demuestra el rol de la mujer en el conflicto intentando relevarla de la posición marginal que comúnmente ocupa en la historia, cuestión más poderosa si se trata de conflictos bélicos decimonónicos donde los héroes patrios, como personajes principales, recaen en la masculinidad. Posteriormente, Juan Carlos Arellano indaga sobre los imaginarios nacionales desplegados en Chile y el Perú durante la guerra a través de los periódicos. Estudia los discursos de la época para identificar las representaciones del enemigo, del pueblo y de la nación. Plantea que el discurso nacionalista exaltó elementos culturales y raciales del enemigo, lo cual vino a entregar un sentido que supera las razones circunstanciales de la guerra. De esta forma, el discurso bélico es asumido como un choque cultural y racial, donde cholo, roto y araucano serán basalto constructor del discurso guerrero. Del mismo modo, Patricio Ibarra analiza las imágenes de los periódicos chilenos que a través del uso de la sátira desacreditaron al enemigo. De esta manera, estudia la difusión en la opinión pública de los grabados que los caricaturistas chilenos realizaron, quienes con un discurso visual agresivo, generaron una representación despectiva de las repúblicas de Perú y Bolivia. Ibarra arguye que la prensa se encargó de construir un "otro" a partir de su difamación, anclándose en el rescate y construcción simbólica del adversario a derrotar.

El artículo de José Chaupis se concentra puntualmente en una evaluación crítica de los manuales escolares y del tratamiento que éstos tienen sobre la guerra, intentando desentrañar la intencionalidad de las casa editoriales con el fin de comprender de qué forma son presentados los actores subalternos en el conflicto. Su trabajo incluye la exposición de contenidos, la combinación de textos, imágenes, fuentes y la presencia de recursos didácticos, materiales que son complementados con el cruce de la producción historiográfica que evidencia una brecha que ha silenciado a los actores subalternos, factor que no permite la integración de los países, en palabras del autor, debido a que aparecen cargados de estereotipos que no reivindican su capacidad de agencia, impidiendo el desarrollo de un pensamiento crítico libre de prejuicios. 
Los profesores José Antonio González, Marcelo Lufin y Claudio Galeno presentan un análisis de la población boliviana que se trasladó a la región de Antofagasta durante el apogeo de la era del nitrato, entre 1880 y 1930. En este artículo, sobre la base de la extensa información archivística, se exponen los rasgos de esta población migrante a través de las variables de origen geográfico de la migración y distribución de género; el capital social del migrante y etapas temporales de la inmigración; los grupos etarios que compusieron el proceso junto a la composición étnica y patrones de nupcialidad. El cruce y análisis de estas variables permiten sostener a los autores que la migración boliviana fue mayoritariamente masculina y joven, de ascendencia criolla, y de regiones distantes de la frontera chilena. Por otra parte, se concluye que la inserción en la sociedad regional operó a través de su incorporación al mercado laboral y mediante patrones de nupcialidad exogámicos.

En otro plano, Cristián Ovando reflexiona sobre la noción de soberanía que está implícita en algunas propuestas bolivianas para la salida soberana al mar, analizando la discusión de una soberanía compartida como premisa clave para construir una zona trinacional de desarrollo, que abarque el norte de Chile, el sur del Perú y el oeste boliviano. El autor se posiciona en la noción de soberanía desde la teoría de las relaciones internacionales, permitiéndole abordar las diversas propuestas con un acento en los aspectos reflectivistas sobre el concepto de soberanía tradicional, y de esta forma, explorar nuevas formas en la delimitación espacial del Estado.

Finalmente, Guillermo Bravo reflexiona sobre las migraciones en el actual contexto de la globalización y mundialización de la economía. Sus antecedentes le permiten explicar por qué el fenómeno demográfico de las migraciones dejan de poseer un carácter económico de subsistencia para convertirse en una compleja trama que el autor sostiene para la seguridad de los países receptores de dichos flujos migratorios.

Con estos interesantes artículos, DIÁLOGO ANDINO sigue abordando temas-problemas con un fuerte contenido histórico, pero que ciertamente repercuten en la actualidad como parte de los espacios reflexivos que las Humanidades y las Ciencias Sociales deben generar en la ciudadanía, sobre todo en los territorios desérticos, donde los antiguos caminantes andinos recorrieron viejas llanuras mucho antes que la repúblicas liberales impusieran sus fronteras.

Campus Saucache, invierno 2015. 
